\title{
Characteristics of natural rubber/latex compound waste (NR/LCW) blends in the perspective of shoe soles application
}

\author{
Ihda Novia Indrajati*, Ike Setyorini, Indah Kumalasari \\ Center for Leather, Rubber and Plastics, Ministry of Industry, Jl. Sokonandi No. 9, Yogyakarta 55166, Indonesia \\ *Corresponding author. Tel. +62 274 512929, Fax. +62 274563655 \\ E-mail: i-novia@kemenperin.go.id
}

Submitted: 19 November 2018

Revised: 28 May 2019

Accepted: 28 May 2019

\begin{abstract}
Being difficult to degrade, latex compound waste (LCW) should be handled carefully. In this study the possibility of application of LCW for shoe sole was evaluated. LCW was derived from latex-based industry from local factory. It was blended with natural rubber (NR) with the ratio ranging from 100/0;90/10;80/20;70/30;60/40 and 50/50. Cure characteristics and mechanical properties including tensile strength, elongation at break, hardness and tear strength, were measured before and after aging. Abrasion loss and slip resistance were also taken account. The results finding showed that crosslink density of the NR/LCW blends were higher than of control. Mechanical properties of the blends were greatly affected by crosslink density. Compared to control, the NR/LCW blends provided lower tensile and elongation, but higher in tear strength, hardness and abrasion loss. Heat aging tended to decrease the mechanical properties. LCW improved the coefficient of friction (CoF).
\end{abstract}

Keywords: latex, waste, shoe sole, coefficient of friction, slip.

\section{INTRODUCTION}

Shoes may be one of the basic need for human being. Basically, the main functions of shoes are protection and comfort. But, some peoples wear shoes to enhance their performance, informs their social status or life quality (Silva et al., 2009; Kim, 2016). Several studies also had proved that shoes have strong relationship with health. They may contribute to health injuries or other fatal accidents such as slip and falls during doing activities (Braunstein et al., 2010; Herbaut et al., 2017). Thus, choosing appropriate shoes for any intended purposes is important. Generally, shoes are composed by two elements, i.e. upper and bottom part (sole). Shoe sole plays important role since it become the first interface between body structures and the ground. When the foot hits the ground during walking or running, the reaction force is damped and the shock wave is then attenuated by the sole (Herbaut et al., 2017). By this definition, shock-absorption capability of shoe sole is critical factor one should consider carefully when designing shoes. Moreover, shoe sole should have good endurance, lightweight (Shimazaki et al., 2016) and provide sufficient slip property (Colonna et al., 2016). Shoe soles are commonly made of plastic, rubber or leather for luxurious purposes. Among them rubber are preferred because of their particular properties such as high tensile and tear strength, wide range of hardness, lower abrasion and durability (Silva et al., 2009).

Natural rubber (NR) is well-known for its excellent mechanical properties including better damping and shock-absorbing properties. Therefore, NR is used in large volume for shoe sole applications. But, because of its limitation properties, for some applications NR is blended with other polymers to achieve the desired properties. Nevertheless, this outstanding property of rubber generates negative impact to the environment. The three dimensional networks of vulcanized rubber are very difficult to degrade due to the complexity of its structure and composition (Medina et al., 2018; Nuzaimah et al., 2018). Thus, the constant growing of rubber wastes becomes serious problem throughout the world. The used-tires dominates the number of rubber wastes. Another types of rubber waste that growing is latex based waste since it is also consumed in large volume to produce several products such as gloves, medical devices, contraceptive, etc. This type of rubber waste is divided into two category, i.e. liquid and solid wastes. Liquid wastes are obtained from latex compound due unstable nature of latex compond and the strict specification regarding the latex product quality. Solid wastes commonly come from rejected or used product. Solid waste can also come from coagulated NR latex (NRL) during maturation or storage period due to unstability of its colloidal system. This solid waste is characterized by soft, liamy and often with less crosslinks. Several efforts have been attempted to overcome this problem. Rubber wastes are mostly recycled and applied to reduce the amount of fresh raw material in the composition, including rubber or filler. In some applications, the rubber wastes need to be reclaimed or desulfurized. Medina et al. (2018) reviewed the possibility of composite with recycled rubber aggregates in construction. Nuzaimah et al., (2018) conducted a comprehensive study in the application of recycled rubber 
waste as fillers. Boondamnoen et al. (2012) blended waste NR latex product with polystyrene in either melt blending or dynamic vulcanization. Dierkes et al. (2007) employed reclaimed-NR latex wastes derived from medical gloves and condoms to substitue virgin NR progressively. However, very few studies is conducted to utilize the latex compound waste. Ramli et al. (2016) have successfully blended latex waste with fresh latex compound for cleaning applicaton.

In this study, solid waste derived from compoundedlatex storage tank (LCW) is progressively incorporated to substitute the virgin NR in shoe sole application. The LCW is used as supplied, without reclamation or desulfurization process. The processing characteristics and mechanical properties are monitored to evaluate the effect of LCW addition within the matrix. Slip resistance is also taken account in the discussion.

\section{MATERIALS AND METHODS Materials}

Natural rubber grades ribbed smoked sheet (RSS) 1, was supplied by local estate PTPN IX Indonesia. Latex waste was supplied by local industry located in West Java, Indonesia (see Figure 1). This is coagulated latex compound found in the storage tank. Zinc oxide (Indoxide) and Aflux $42 \mathrm{M}$ (Rhein Chemie) were employed as activator. Carbon black class N-330 and N-660 (Ex. OCI), and local silica were used as filler. Antioxidant 2,2,4-Trimethyl-1,2Dihydroquinoline (TMQ) (Kemai), antiozonant N-(1,3Dimethylbutyl)-N'-phenyl-p-phenylenediamine (6PPD) (Northeast) and paraffin wax Antilux 654 A (Rhein Chemie) were used as antidegradant system. Accelerators system comprised to 2,2'-Dithiobis(benzothiazole) (MBTS) (Shandong Sianxian) and diphenyl guanidine (DPG) (Shandong Shianxian). Sulfur Midas SP 325 (Miwon) was used as vulcanizing agent. All chemicals were supplied in industrial grade.

\section{Methods}

\section{Latex waste characterization}

Characterization was carried out to investigate the existing crosslink in the LCW before blended with NR and other ingredients. Crosslink density of the LCW was determined both by equilibrium swelling and Rheometer test.

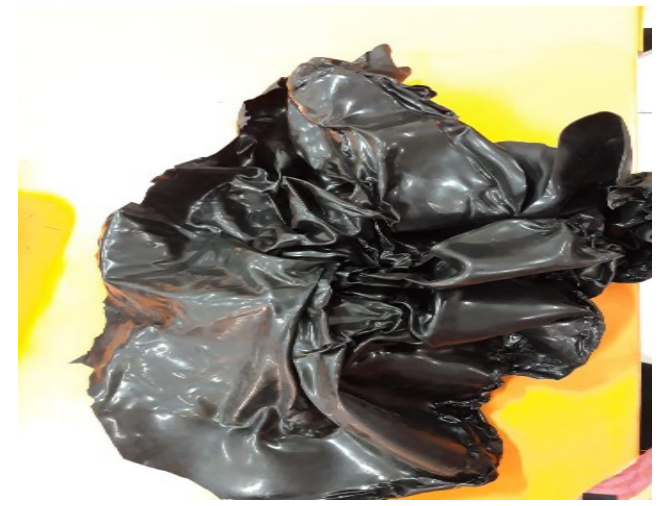

Figure 1. LCW when supplied.
Crosslink density measurement by equilibrium swelling

The principle of this method is determining crosslink density by measuring the absorbed liquid in the rubber sample. An $8 \mathrm{~g}$ of LCW was immersed in toluene for $72 \mathrm{~h}$ at ambient temperature. After completion swelling period, the sample was taken out and blotted with tissue paper to remove excess solvent. The mass sample, initial $\left(w_{0}\right)$ and final $\left(w_{f}\right)$, were weighed using analytical balance with $0.0001 \mathrm{~g}$ accuracy. The crosslink density was calculated using the Flory-Rehner equation as defined on equation 1 ,

$$
M_{c}=\frac{-\rho_{p} V_{s} V_{r}^{\frac{1}{8}}}{\left[\ln \left(1-V_{r}\right)+V_{r}+\mathrm{X} V_{r}^{2}\right]}
$$

where $M_{c}$ is the number average molecular weight of the rubber chains between crosslink; $\rho_{p}$ is density of the polymer; $V_{s}$ is molar volume of the solvent (for toluene $\left.V_{s}=106.2 \mathrm{~cm}^{3} \mathrm{~mol}^{-1}\right), V_{r}$ is molar volume of rubber, $X$ is polymer-solvent interaction parameter (for NRtoluene=0.42). The term $V_{r}$ was calculated by using the relation as expressed on equation 2.

$$
V_{r}=\frac{\frac{w_{1}}{\rho_{1}}}{\left(\frac{w_{1}}{\rho_{1}}+\frac{w_{2}}{\rho_{2}}\right)}
$$

$w_{1}, \rho_{1}$ are the weight and density of rubber, while $w_{2}, \rho_{2}$ are the weight and density of solvent.

\section{Curing test}

Crosslink density is determined by monitoring the torque changes during testing. The more crosslinks formed, the higher torque is. Curing test was performed on a rotorless Moving Die Rheometer (MDR) Gotech M3000A. A fixed angle of $3^{\circ}$ was applied and the frequency was $100 \mathrm{cpm}$. The tests were performed during 10 minutes or until the maximum torque $(\mathrm{MH})$ achieved. The data derived from the instrument included minimum (ML) and maximum (MH) elastic torques, scorch time $\left(\mathrm{ts}_{2}\right)$, curing time $\left(\mathrm{t}_{90}\right)$ and cure rate. MDR also measured viscous torques (S") that useful to predict the viscoelasticity coupled with elastic torques. The ratio of viscous to elastic torque, expressed as $\tan \delta$, explains the damping properties that relates to energy absorption of a rubber compound on certain deformation rate. Thus, it can be applied to estimate the shock absorption property of shoe sole.

\section{Compounds preparation and vulcanization}

The blends were prepared according to the formulation on Table 1 and mixed in a two roll mill laboratory scale in a constant sequence batch to batch. NR was first masticated, and then mixed with LCW. This step was followed by another additive incorporation. After completion of mixing process, the compound was soaked in cool water for 5 minutes in order to terminate the pre vulcanization which may be occurred during mixing because of heat generated by shearing action. Compounds were allowed to rest $24 \mathrm{~h}$ at $25^{\circ} \mathrm{C}$ before subsequent processes or testing. 
Table 1. The formulation of rubber soles.

\begin{tabular}{ccccccc}
\hline \multirow{2}{*}{ Ingredients } & \multicolumn{7}{c}{ Concentration (phr) } \\
\cline { 2 - 6 } & S0 & S1 & S2 & S3 & S4 & S5 \\
\hline NR (RSS 1) & 100 & 90 & 80 & 70 & 60 & 50 \\
LCW & 0 & 10 & 20 & 30 & 40 & 50 \\
ZnO & 5 & 5 & 5 & 5 & 5 & 5 \\
Aflux 42 M & 1.5 & 1.5 & 1.5 & 1.5 & 1.5 & 1.5 \\
N-330 & 40 & 40 & 40 & 40 & 40 & 40 \\
N-660 & 20 & 20 & 20 & 20 & 20 & 20 \\
Silica & 15 & 15 & 15 & 15 & 15 & 15 \\
Paraffinic oil & 8 & 8 & 8 & 8 & 8 & 8 \\
TMQ & 2 & 2 & 2 & 2 & 2 & 2 \\
6PD & 1 & 1 & 1 & 1 & 1 & 1 \\
Paffin wax & 0.5 & 0.5 & 0.5 & 0.5 & 0.5 & 0.5 \\
MBTS & 1.5 & 1.5 & 1.5 & 1.5 & 1.5 & 1.5 \\
DPG & 0.2 & 0.2 & 0.2 & 0.2 & 0.2 & 0.2 \\
Sulfur & 2.5 & 2.5 & 2.5 & 2.5 & 2.5 & 2.5 \\
\hline
\end{tabular}

Vulcanization was carried out by compression molding in a hydraulic press with two hot platens (upper and lower). The pressure applied was $150 \mathrm{~kg} / \mathrm{cm}^{2}$ and temperature of $150{ }^{\circ} \mathrm{C}$. The vulcanization time was determined based on the curing time $\left(t_{90}\right)$ obtained from Rheometer test of each compound. The dimension of cured rubber was prepared according to the requirements of each test. Tensile properties and tear strength used a 2-mmthick slab cured rubber samples. Hardness was measured using a $12-\mathrm{mm}$-thick disc circular sample with diameter of $29 \mathrm{~mm}$. Cured rubber samples were conditioned for at least $16 \mathrm{~h}$ before testing.

\section{Mechanical properties testing}

Tensile strength and elongation at break were measured using universal testing machine Tinius Olsen $\mathrm{H}$ $50 \mathrm{~K}$, in accordance to ISO 37. A dumbbell-type specimen was used and crosshead rate of $100 \mathrm{~mm} / \mathrm{min}$. Tear strength testing was carried out in the same instrument according to ISO 34. An angle-type specimen was employed. The results of the tests were obtained directly from the instrument. Hardness of the blends were tested in accordance to ISO 48 using Shore A durometer. A 12-mm thick specimen of cured rubber was used for this test. DIN Abrasion resistance was measured following ISO 4649. Similar specimen to hardness testing was applied. All the test except DIN abrasion were performed on before and after heat aging according to ISO 188. Air circulated oven was used to conduct aging process. The retention value after aging was calculated using Equation 3 to predict the remaining value of each parameter.

$$
\text { Retention }(\%)=\frac{\text { value after aging }}{\text { value beforeaging }} \times 100 \%
$$

\section{Slip resistance measurement}

Slip resistance testing in accordance to ISO 13287 was conducted to determine the coefficient of friction (CoF). Prototype of shoe soles were employed in this test as depicted on Figure 2. SATRA slip resistance tester STM 603 was used to conduct this measurement. The data generated and calculated using slipMASTER software version 3.2.0.1.

\section{RESULTS AND DISCUSSION}

\section{LCW Characteristics}

Crosslink density is estimated to quantify the preexisted crosslinks in LCW before blended with virgin NR. Table 2 lists the crosslink density estimated by both equilibrium swelling and curing test methods. Equilibrium swelling measures total crosslink density (both chemical and physical crosslinks) of the LCW samples. Rheometer estimates the crosslink density through the highest torque achieved during experiment (MH), while ML representing the physical crosslink formed before curing, as a result of rubber-filler interaction or chains entanglement. It is evident that LCW contains crosslink but in low density compared to the NR/LCW blends as seen on Figure 3 and Figure 6 . The pre-existed crosslinks could give benefit to the blends mechanical properties. On the other hands, however, crosslink will increase the viscosity of the LCW and will generate a problem when mixed with virgin NR.
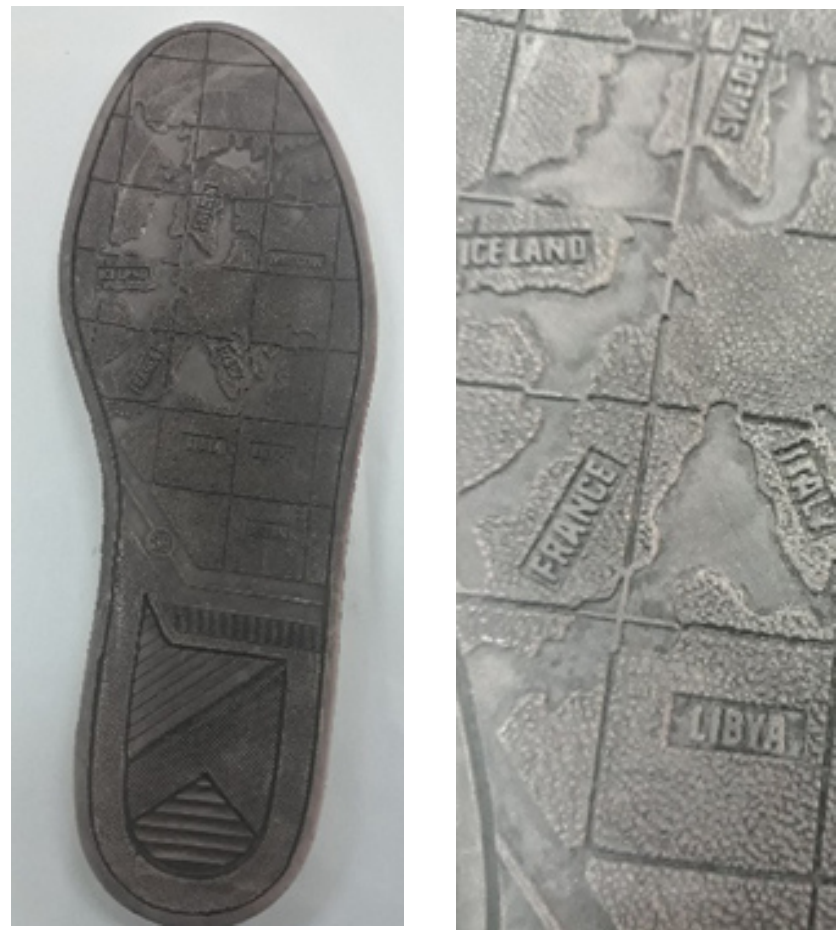

Figure 2. Specimen for CoF determination. 
Table 2. Crosslink density of LCW.

\begin{tabular}{lcc}
\multicolumn{1}{c}{ Methods } & Unit & Crosslink density \\
\hline Swelling & $\mathrm{mol} / \mathrm{cm}^{3}$ & $2.78 \times 10^{-5}$ \\
Curing test & & 13.83 \\
Max. torque $(\mathrm{MH})$ & $\mathrm{kgf.cm}$ & 3.92 \\
Min. torque $(\mathrm{ML})$ & $\mathrm{kg} . \mathrm{cm}$ & \\
\hline
\end{tabular}

\section{Processing and Cure Characteristics}

A perfect shoe sole is not only depended on the ingredients on the formulation, but also the processing. Homogeneous matrix and well-distributed additives should be obtained during mixing. Then, rubber compound have to flow properly during shaping or molding. Rubber shoe soles usually produce in one way curing in which shaping and curing are conducted in one time. Therefore, a good flow characteristic coupled with sufficient scorch time are needed. Typically, curing process is divided into three steps, i.e. induction, curing and post curing. Shaping is occurred during induction period $\left(t<\mathrm{ts}_{2}\right)$. During this period, rubber compound should flow within certain time to fulfill the mold cavities. The ts ${ }_{2}$ is the onset of curing (or vulcanization) that means as the end of induction period. Incomplete product dimension and design probably becomes a problem generated because rubber compound possesses worse flow characteristic and short ts. Viscosity of rubber compound can describe the flow characteristic. Minimum torque (ML) roughly represents the uncured rubber viscosity. It is also a measure of physical crosslink that formed as a result of rubber-filler particles interaction or chains entanglement (Surya et al., 2013). The ML contributes to the processing properties

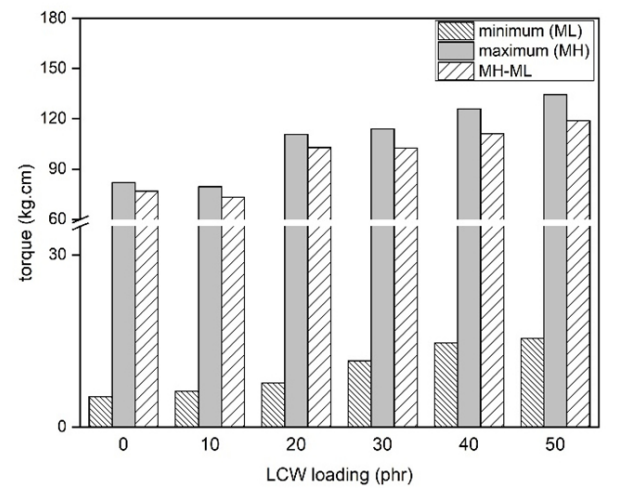

Figure 3. Rheometer torques of the NR/LCW blends.

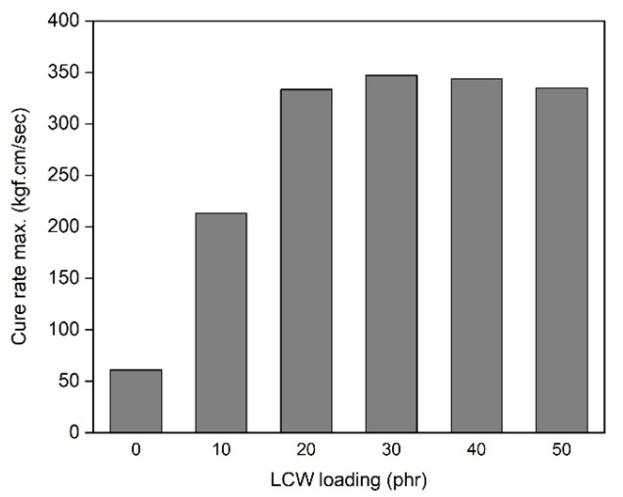

Figure 5. Cure rate maximum of the NR/LCW blends at $150{ }^{\circ} \mathrm{C}$.
(Formela et al., 2015). Figure 3 evidently shows that incorporation of LCW tends to increase the viscosity of the NR/LCW blend represented by the increasing of ML. This is probably caused by the existed crosslink on LCW. Similar to ML, ts, also shows dependency on LCW loading as depicted on Figure 4. Since LCW used without reclamation, it may contain accelerator in certain amount. This will increase the accelerator level in the formulation and in turn takes a part in curing process. Thus, a reduction on $\mathrm{ts}_{2}$ is found upon LCW addition. The addition $30 \mathrm{phr}$ of LCW significantly reduces ts, up to $25 \%$. High viscosity and short ts ${ }_{2}$ will be harmful and increase the possibility of rejected product.

Crosslinks are formed during curing period. The highest crosslink formed is represented by MH. It also indicates the stiffness level of rubber compound. Increasing LCW content leads to rise the $\mathrm{MH}$ as displayed on Figure 3. Curatives content in LCW may contribute to this finding. It is interesting to note here that the optimum cure time $\left(\mathrm{t}_{90}\right)$ decrease with LCW increment (Figure 4). This is probably contributed by higher cure rate as depicted on Figure 5. Low $t_{90}$ brings positive effect related to the energy consumption and thus of the cost because the vulcanization reaction proceeds faster.

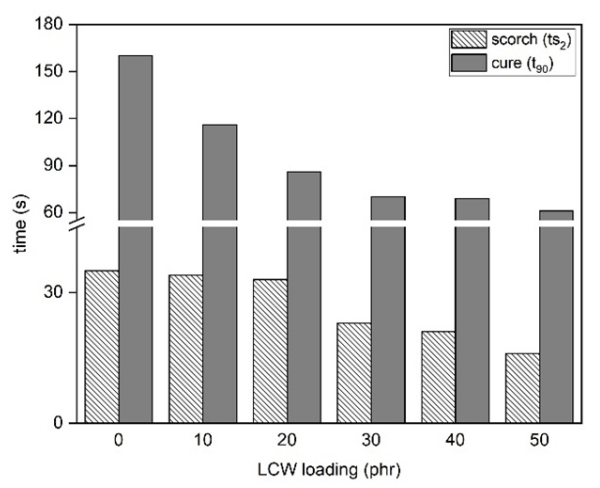

Figure 4. Scorch $\left(\mathrm{ts}_{2}\right)$ and optimum curing time $\left(\mathrm{t}_{90}\right)$ of the NR/LCW blends.

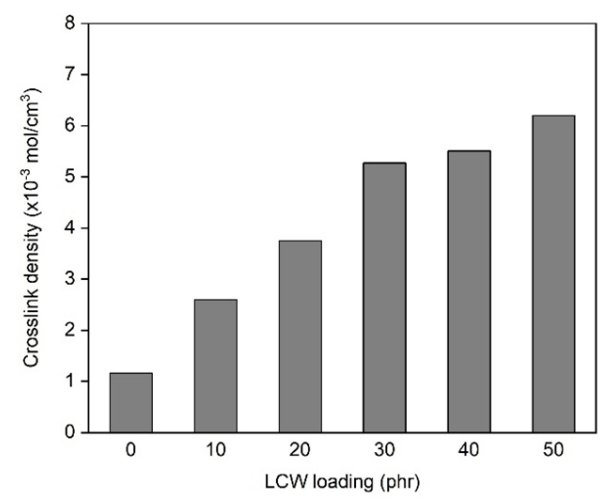

Figure 6. Crosslink density measured by equilibrium swelling. 
The torque difference (MH-ML) is indirect measure of the net crosslink formed during curing period. It looks linear to the LCW loading. Crosslink density also measured using equilibrium swelling method and the results are displayed on Figure 6. Crosslink increases significantly by the increment of LCW. It is almost doubled on $10 \mathrm{phr}$ of LCW. This finding is agreed to the crosslink density measurement by rheometer. High density of crosslink in rubber gives positive effect on mechanical properties, but in one time they will decrease. Thus, careful consideration should be taken to set up a formulation that provides balanced properties.

\section{Shock Absorption Prediction}

The definition of comfortable provides by a shoes is not only related to its color or design, but also affected by several factors including fitting, inner thermal and humidity environment, plantar pressure distribution and ground impact forces. Among these factors, ground impact forces is one aspect that takes into consideration. It not only determines comfort or discomfort, but may also induce injuries during activities. The ground forces impact can be explained by the ability of shock absorption of a shoe sole. Shock absorption properties of a rubber sole can be roughly estimated by measuring tangent phase $(\tan \delta)$ from MDR experiment. Tan $\delta$ is damping factor that strongly related to the energy absorption on certain deformation rate. For shoe sole application, high $\tan \delta$ is needed. High $\tan \delta$ means the cured rubber absorbs and dissipates much of applied energy. High $\tan \delta$ is achieved when viscous torque is higher than of elastic torque or less crosslinking in matrix.

Figure 7 clearly depicts the reduction of $\tan \delta$ by addition of LCW. It is reduced almost $20 \%$ on addition of $10 \mathrm{phr}$ LCW and further addition tends to decrease. This reduction probably is correlated to the increasing of crosslink density. Crosslink causes elastic modulus to increase, and automatically decreases $\tan \delta$. This finding indicates negative impact on shock absorption properties of shoe sole.

\section{Mechanical Properties of the Sole}

The LCW loading gives different response on the mechanical properties of the blends. Figure 8 represent

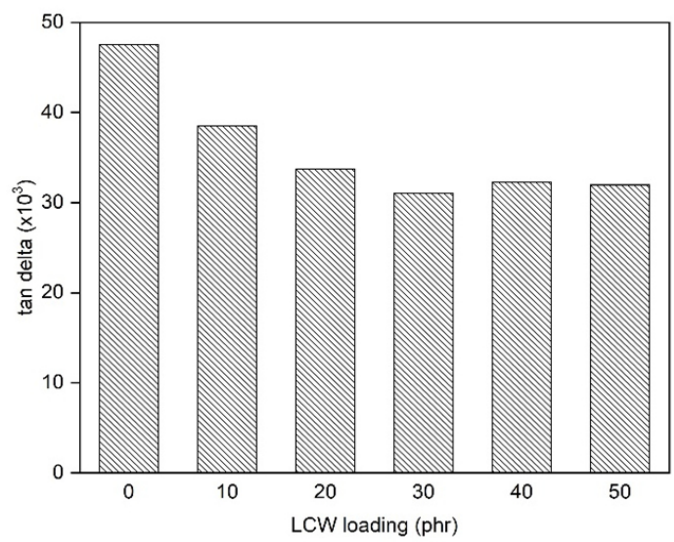

Figure 7. Tan $\delta$ of the cured NR/LCW blends. the effect of LCW loading on tensile strength. Addition of LCW generate detrimental effect on tensile strength of the blends, and its effect more severe in higher loading. Even though higher LCW loading provides higher crosslinking, but it does not result in better tensile strength. When crosslink density is too high, the length between two points of crosslink is greatly reduced that lead to a decrease of the mobility of rubber molecule chains (Zhao et al., 2011). The ability of rubber network to dissipate input energy through molecular motion is decreased, and then the rubber becomes more brittle. That is the tensile strength goes down upon increasing crosslinking. Other factor affecting tensile strength is the structure of rubber. NR is being strain-induced crystalline rubber. The molecule chains will be rearranged to form closely packed structure that turns amorphous phase into crystalline. This structure will provide better strength. Increasing LCW content within the matrix consequently reduces the NR fraction. This probably decrease the ability to form a crystalline structure induced by stretching. Thus, lower the tensile strength is observed.

Similar to tensile strength, tear strength of the NR/ LCW blends are decreasing with LCW content as seen on Figure 9. But surprisingly they are slightly higher than of with only NR ( 0 phr LCW). Tear resistance is related to the ability of rubber network to resist the cut growth of initiate crack.

The elongation at break and hardness often used to describe the elasticity of rubber vulcanizates. Theoretically, both parameters are influenced by the crosslink density. In this study, it is found that elongation at break is greatly reduced by increasing crosslink density as observed on Figure 10. Incorporation high loading of LCW makes the rubber matrix less elastic. Too high crosslinking in rubber network will cause an increase of stiffness that lead to a decrease in elongation. This supports the explanation for the reduction of tensile strength caused by denser crosslinked network. Inversely to elongation at break, hardness of the blends is slightly increase upon LCW loading (Figure 11). But, the incorporation of LCW does not make a marked increase in hardness. Ultimate hardness of the blends is around 80 Shore A. This value probably will affect the slip resistance in shoe sole application since hardness is the critical parameter of it.

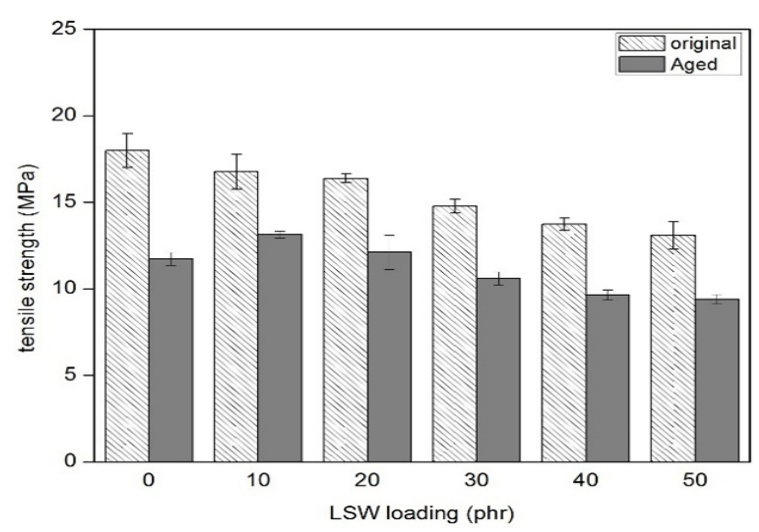


Heat aging is observed to decrease the tensile and tear strength and elongation at break. But it only causes small change on hardness. The retained value after aging of each property is presented on Figure 12. Retention of tensile, elongation and hardness of the NR/LCW blends are comparable to those of control. But, retention of tear strength is much lower than those of control. Reduction of mechanical properties of the blends is perhaps related to the effect of heat aging on the rubber network. The main reaction during heat aging is oxidative that may cause chain scission, crosslinking or polymer interphase modification. Crosslink type contributes to the aging resistance because they have different bonding energy (Naebpetch et al., 2016). Polysulfide linkage (C-S $-\mathrm{x}$, with $\mathrm{x}>2$ ) has the lower bonding energy thus prone to degrade when expose to prolong heat or oxidative reaction. Reduction of tensile, tear strength and elongation at break probably caused by chain scission that dominates during the oxidative aging.

Abrasion loss is observed to increase slightly upon LSW loading as seen on Figure 13. Abrasion resistance is affected by volume fraction of the filler, crosslink density and rubber-filler interaction. In this study, the filler content

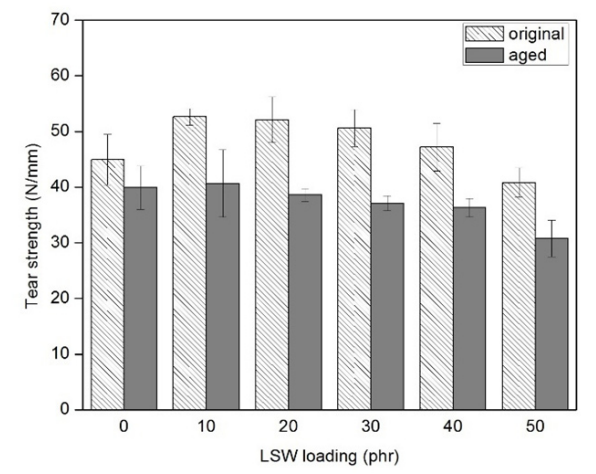

Figure 9. Tear strength of the NR/LCW blends.

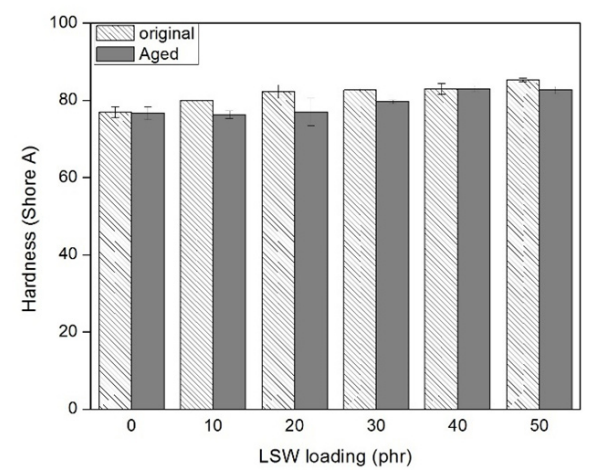

Figure 11. Hardness of the blends.

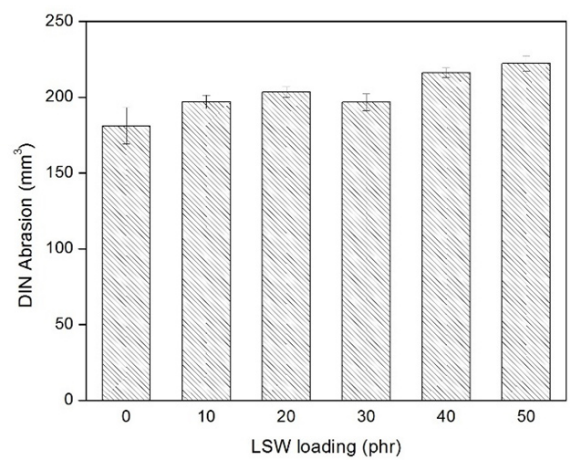

Figure 13. DIN abrasion of the blends. in the formulation is constant thus the effect of volume fraction may be neglected.

\section{Slip Resistance}

The possibility of slip comes when the friction required to sustain gait exceeds the friction available from the shoe/floor interface (Tsai \& Powers, 2009; Iraqi et al., 2018). Coefficient of friction (CoF) likely measures to describe the slip resistance of shoes. Friction is defined as the force resistance to relative motion generated between two materials in contact with another. It involves two interfacing and interacting surfaces. Hence, the surface condition and thread design of the sole should be considered to identify the frictional characteristic and slip properties (Kim, 2016). Another factor that influence slip is the sole material that determines the hardness. Harder soles typically give less available friction than of softer soles. Thus, people who wear harder soled shoes will have greater risk for slip occurrence (Tsai \& Powers, 2009). Figure 14 represents the $\mathrm{CoF}$ between the standard surface and the soles. LCW improves CoF compared to control, and is dependent on hardness.

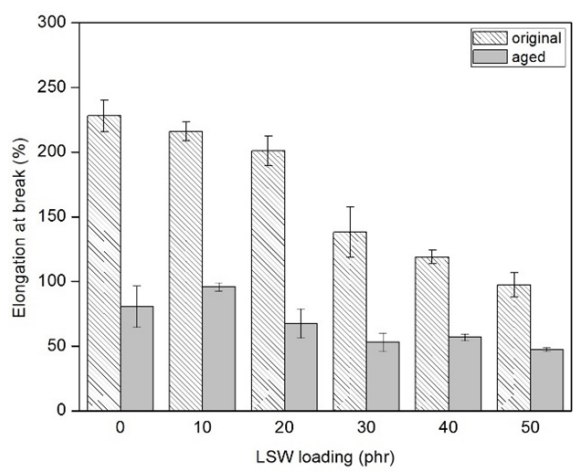

Figure 10. Elongation at break of the blends.

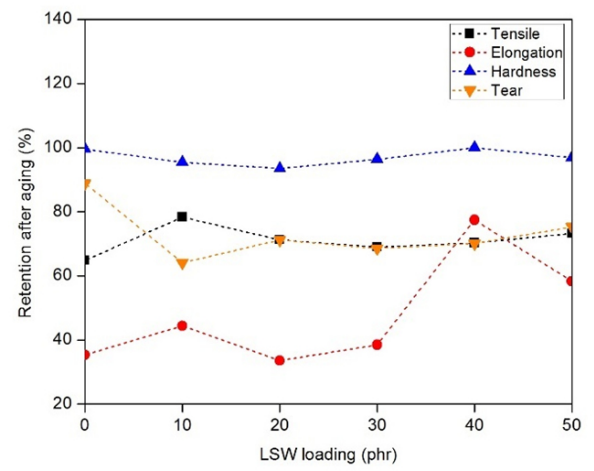

Figure 12. Retention value after heat aging.

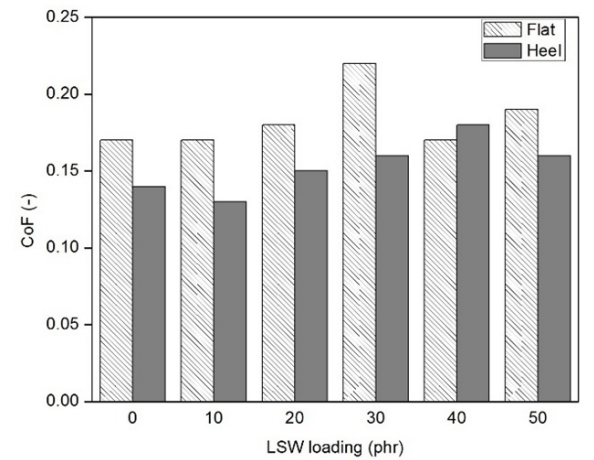

Figure 14. Coefficient of friction $(\mathrm{CoF})$ of the blends. 


\section{CONCLUSIONS}

Latex compound waste (LCW) had been successfully blended with natural rubber for shoe sole application. LCW was characterized to have crosslink in low density and still contains curatives that was available to take part in further crosslinking. Addition of LCW into the rubber matrix gradually decreased scorch time $\left(\mathrm{ts}_{2}\right)$ and optimum curing time $\left(\mathrm{t}_{90}\right)$. Minimum (ML) and maximum $(\mathrm{MH})$ torques were found to increase upon LCW loading. Consequently, the torque difference also rose up that represented crosslink density of the blends. Shock absorption of the blends was predicted through analyzing the damping factor $(\tan \delta)$. LCW generated negative effect by decreasing the damping factor that meant reduction of the ability of absorbing shock. The NR/LCW blends exhibited lower tensile strength and elongation at break compared to control ( 0 phr LCW), while tear strength and hardness slightly higher. These properties were also greatly affected by crosslink density. Aging gave different response on mechanical properties. Marked reduction was found on tensile strength, elongation at break and tear strength, but the retained value of each parameter was relatively constant respect to LCW loading. Elongation at break provided the lowest retention value compare to other three parameters. Hardness showed a little change by heat aging. Abrasion loss gradually increased with LCW loading. Coefficient of friction $(\mathrm{CoF})$ was improved by LCW addition into the matrix.

\section{ACKNOWLEDGEMENT}

The authors would like to thank to PT. Sugih Waras Instrumendo for supplying the LCW. The authors would also grateful to the Indonesian Footwear Industry Development Center, Ministry of Industry Republic of Indonesia for assisting the slip experiments.

\section{REFERENCES}

Boondamnoen, O., Ohshima, M., Azura, A. R., Chuayjuljit, S., \& Arifin, A. (2012). Recycling waste natural rubber latex by blending with polysterene - Characterization of mechanical properties. International Journal of Modern Physics: Conference Series, 06, 391-396. https://doi.org/10.1142/S2010194512003492

Braunstein, B., Arampatzis, A., Eysel, P., \& Brüggemann, G. P. (2010). Footwear affects the gearing at the ankle and knee joints during running. Journal of Biomechanics, 43(11), 2120-2125. https://doi.org/10.1016/j.jbiomech.2010.04.001

Colonna, M., De Bon, F., Tarterini, F., Moncalero, M., Totaro, G., Gioia, C., \& Fabbri, P. (2016). Ski boot soles based on a glass fiber/rubber composite with improved grip on icy surfaces. Procedia Engineering, 147, 372-377. https://doi.org/10.1016/j.proeng.2016.06.316

Dierkes, W. K., Rajan, V. V., Noordermeer, J. W. M., \& Joseph, R. (2007). Application of NR-based latex reclaim: The link between structure and properties. Rubber Chemistry and Technology, 80(1), 40-60. https://doi.org/10.5254/1.3548168

Formela, K., Wąsowicz, D., Formela, M., Hejna, A.,
\& Haponiuk, J. (2015). Curing characteristics, mechanical and thermal properties of reclaimed ground tire rubber cured with various vulcanizing systems. Iranian Polymer Journal, 24(4), 289-297. https://doi.org/10.1007/s13726-015-0320-9

Herbaut, A., Chavet, P., Roux, M., Guéguen, N., Barbier, F., \& Simoneau-Buessinger, E. (2017). The influence of shoe aging on children running biomechanics. Gait and Posture, 56, 123-128. https://doi.org/10.1016/j.gaitpost.2017.05.011

Iraqi, A., Cham, R., Redfern, M. S., \& Beschorner, K. E. (2018). Coefficient of friction testing parameters influence the prediction of human slips. Applied Ergonomics, 70, 118 126. https://doi.org/10.1016/j.apergo.2018.02.017

Kim, I. J. (2016). Identifying shoe wear mechanisms and associated tribological characteristics: Importance for slip resistance evaluation. Wear, 360-361, 77-86. https://doi.org/10.1016/j.wear.2016.04.020

Medina, N. F., Garcia, R., Hajirasouliha, I., Pilakoutas, K., Guadagnini, M., \& Raffoul, S. (2018). Composites with recycled rubber aggregates: Properties and opportunities in construction. Construction and Building Materials, 188, 884-897. https://doi.org/10.1016/j.conbuildmat.2018.08.069

Naebpetch, W., Junhasavasdikul, B., Saetung, A., Tulyapitak, T., \& Nithi-Uthai, N. (2016). Influence of accelerator/ sulphur and co-agent/peroxide ratios in mixed vulcanisation systems on cure characteristics, mechanical properties and heat aging resistance of vulcanised SBR. Plastics, Rubber and Composites, 45(10), 436-444. https://doi.org/10.1080/14658011.2016.1244029

Nuzaimah, M., Sapuan, S. M., Nadlene, R., \& Jawaid, M. (2018). Recycling of waste rubber as fillers: A review. IOP Conference Series: Materials Science and Engineering, 368, 012016. https://doi.org/10.1088/1757-899X/368/1/012016

Ramli, N. F., Dzulkafly, N. S., \& Rashid, A. A. (2016). Utilization of waste natural rubber latex for cleaning application. Advanced Materials Research, 1133, 221-225. https://doi.org/10.4028/www.scientific.net/ AMR.1133.221

Shimazaki, Y., Nozu, S., \& Inoue, T. (2016). Shock-absorption properties of functionally graded EVA laminates for footwear design. Polymer Testing, 54, 98-103. https://doi.org/10.1016/j.polymertesting.2016.04.024

Silva, R. M., Rodrigues, J. L., Pinto, V. V., Ferreira, M. J., Russo, R., \& Pereira, C. M. (2009). Evaluation of shock absorption properties of rubber materials regarding footwear applications. Polymer Testing, 28(6), 642-647. https://doi.org/10.1016/j.polymertesting.2009.05.007

Surya, I., Ismail, H., \& Azura, A. R. (2013). Alkanolamide as an accelerator, filler-dispersant and a plasticizer in silica-filled natural rubber compounds. Polymer Testing, 32(8), 1313-1321. https://doi.org/10.1016/j.polymertesting.2013.07.015

Tsai, Y. J., \& Powers, C. M. (2009). Increased shoe sole hardness results in compensatory changes in the utilized coefficient of friction during walking. Gait and Posture, 30(3), 303306. https://doi.org/10.1016/j.gaitpost.2009.05.019

Zhao, F., Bi, W., \& Zhao, S. (2011). Influence of crosslink density on mechanical properties of natural rubber vulcanizates. Journal of Macromolecular Science, Part B, 50(7), 1460-1469. https://doi.org/10.1080/00222348.2010.507453 
